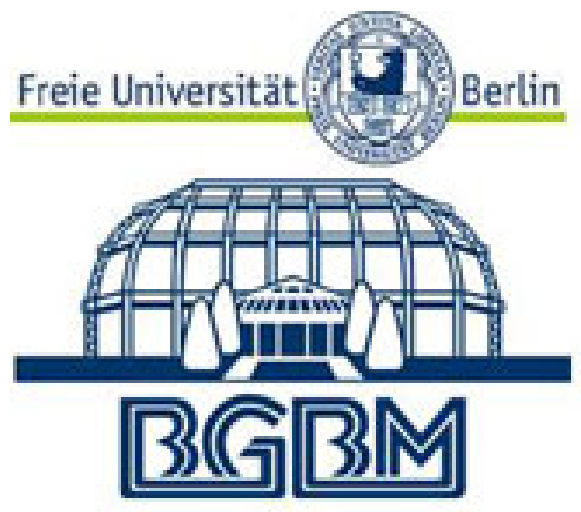

Eine neue Sedum-Art aus dem botanischen Garten in Dahlem

Author(s): E. Ulbrich

Source: Notizblatt des Königl. botanischen Gartens und Museums zu Berlin, Bd. 7, Nr. 63 (May 15, 1917), pp. 111-112

Published by: Botanischer Garten und Botanisches Museum, Berlin-Dahlem

Stable URL: http://www.jstor.org/stable/3994505

Accessed: $14 / 06 / 2014$ 02:55

Your use of the JSTOR archive indicates your acceptance of the Terms \& Conditions of Use, available at http://www.jstor.org/page/info/about/policies/terms.jsp

JSTOR is a not-for-profit service that helps scholars, researchers, and students discover, use, and build upon a wide range of content in a trusted digital archive. We use information technology and tools to increase productivity and facilitate new forms of scholarship. For more information about JSTOR, please contact support@jstor.org. 


\section{Eine neue Sedum-Art aus dem botanischen Garten in Dahlem.}

\section{Von}

\section{E. Ulbrich.}

Sedum aoikon Ulbrich n. sp. - Frutex usque metralis parce ramosus, ramis teretibus laevibus vetustioribus basi usque $1 \mathrm{~cm}$ et ultra crassis cortice griseo obtectis, flexuosis junioribus lucidis saepius subrosaceis, apice solum foliigeris. Folia obovata usque spathulata ad $45 \mathrm{~mm}$ longa, ad $25 \mathrm{~mm}$ lata obtusa vel subemarginulata, ad $3 \mathrm{~mm}$ crassa, laevia, lucida, utrinque aeque viridia vel subtus vix dilutiora, ramorum florigerorum obovata, basin versus subspathulata, ramorum sterilium spathulata, caduca omnia. Inflorescentiae ad ramorum terminos multiflorae, densae, subglomerato-panniculatae, foliosae; ramuli florigeri infimi ad $15 \mathrm{~mm}$ longi, omnes in axillis foliorum ovalium sessilium crassissimorum; flores lutei, sessiles pentameri ad $10 \mathrm{~mm}$ diametr., calyx usque fere basin fissus lobis $1,5-2 \mathrm{~mm}$ longis lanceolatis usque lineari-lanceolatis obtusiusculis inaequalibus; corollae petala lutea cymbiformia, lanceolata acuta ad $5 \mathrm{~mm}$ longa, 1-1,5 mm lata; stamina 10 protandra carpidiis multo breviora, filamentis filiformibus fere $2-2,5 \mathrm{~mm}$ longis tertia parte suprema subito attenuatis luteis antheris globosis fere $0,2 \mathrm{~mm}$ diamet; ovaria 5 sessilia glaberrima flavoviridia in stylum sensim angustata multiovulata; stigmata minuta punctiformia.

Patria ignota in horto botanico berolinensi in hibernaculis plantarum Dahlemensibus culta, florens mense Martio-Aprili.

Ihrer systematischen Stellung nach gehört die Art in den Verwandtschaftskreis von Sedum dendroideum Moç. et Sessé, S. oxypetalum H. B. K., S. tuberculatum Rose und $S$. praealtum A. DC., die sämtlich in Mexiko heimisch sind und sich von $S$. aoikon Ulbrich durch viel größeren und lockeren Blütenstand unterscheiden. Am nächsten kommt S. oxypetalum H. B. K. Alle diese Arten bilden innerhalb der Gattung Sedum eine eigene Gruppe.

Die neue Art wird im botanischen Garten schon seit einer Reihe von Jahren kultiviert. Von wem sie zuerst gesammelt wurde und wie sie in den Besitz des Gartens gekommen ist, ließ sich nicht ermitteln. 
Als Heimat dürfte wohl wie bei den verwandten Arten Mexiko in Frage kommen.

Die neue Art ist leicht kenntlich an ihrem eigenartigen Wuchs, den dicken, glatten, hin- und hergebogenen, nur an ihren Enden beblätterten Zweigen, die in der Jugend oft rötlich überlaufen, im Alter mit glatter, grauer Rinde bekleidet sind. Die dickfleischigen, glänzenden Blätter sind an den blühenden Trieben kleiner und eiförmig, an den nicht blühenden dagegen mehr spatelförmig. Zweige und Blätter brechen leicht ab und lassen sich leicht zur Vermehrung benutzen. Das wichtigste Merkmal ist der reichblütige, dichtgedrängte Blütenstand, der die Art vor allen verwandten auszeichnet. 